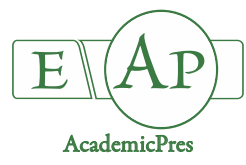

\title{
Evolution of Polyphenols, Flavonoids, and Tannins Content in Walnut Leaves and Green Walnut Husk during Growing Season
}

\author{
Simona GIURA ${ }^{1,2}$, Mihai BOTU ${ }^{1,2}$, Mădălina VULPE³ \\ Loredana Elena VÎJAN ${ }^{3 *}$, Rodi MITREA ${ }^{1}$ \\ ${ }^{1}$ University of Craiova, Faculty of Horticulture, 13 A.I.Cuza Street, Craiova, Dolj, Romania; simona_vam01@yahoo.com; \\ btmihai2@yahoo.com; rodimitrea@yahoo.com \\ ${ }^{2}$ Fruit Growing Research and Extension Station (SCDP) Vâlcea, 464 Traian Street, Râmnicu Vâlcea, Vâlcea, Romania; stpomvl@onix.ro \\ ${ }^{3}$ University of Pitești, 1 Târgu din Vale Street, Pitești, Argeş, Romania; tudorradumadalina@yahoo.com; \\ loredana.vijan@upit.ro (*correspondingauthor)
}

\begin{abstract}
The walnut leaves and the green walnut husk are been widely used in folk medicine. These vegetal materials have been reported as a source of bioactive molecules such as the phenolic compounds. In this research, there were analysed different quality parameters afferent to several walnut varieties, harvested from the germplasm collection located at S.C.D.P. Vâlcea, Romania. Romanian cultivars 'Jupâneşti', 'Valrex' and 'Valmit' and French one 'Franquette' were analyzed. The variation in bioactive compounds content from the walnut leaves and walnut husk at different developmental stages (from June to September) was investigated. The results showed that the content in polyphenols, flavonoids and tannins has significantly increased until the ripening stage, after that a decrease of the values of these parameters follows. Greater values of the three parameters were also observed at walnut leaves and green walnut husk of cultivars attacked by walnut blight, caused by the bacterium Xanthomonas arboricola pv.juglandis (Xaj). The findings of this study reveal the mode of variation in the content of polyphenols, flavonoids and tannins during the growing season of the walnut leaves and green walnut husk, emphasizing also the influence of $X a j$. The results obtained demonstrated the potential of the walnut leaves and the green walnut husk as an economical source of antioxidant and antimicrobial agents.
\end{abstract}

Keywords: flavonoids; green walnut husk; Juglans regia L.; polyphenols; tannins; walnut leaves; Xanthomonas arboricola pv. juglandis

\section{Introduction}

The common walnut (Juglans regia L.), known as English or Persian walnut, considered one of the oldest tree species, is important both from both economically and nutritionally, due to the quality of its fruits, the superior quality of the wood and its other organs. As a technical plant, the walnut provides the raw material for many branches of industry. It is appreciated for its wood with high quality, having high strength, plasticity and finesse, being used in the manufacture of the luxury furniture, the sculpture, in the aircraft and car industry. The walnut is also used as a medicinal plant. The walnut leaves juice is used as a vermifuge, as a tonic, as an ointment for varicose veins, as urine disinfectant. The homeopathy followers recommend the mesocarp for the treatment of acne, irritation, vomiting.
As an ecological plant, walnut is irreplaceable because it is one of the few trees that absorb the heavy metals from the atmosphere. Although it grows slowly due to its highly developed roots, the walnut is used against the soil erosion and the landslides. Thus, being at the same time a technical, forestry, medicinal, dendrological and ameliorative plant, the walnut is unquestionably considered to be one of the most important tree species in our country.

Green and dry walnut leaves are been widely used in folk medicine for the infusions, treatment of skin inflammations, ulcers and for its antiseptic and astringent properties (Pereira et al., 2007; Almeida et al., 2008). Green walnut husk is an agro-forest waste generated in the walnut harvest that could be valued as a source of natural compounds with antioxidant and antimicrobial properties (Fernández-Agulló et al., 2013). It is the basic material for the traditional walnut liqueur (Stampar et al., 2006). 
Walnut and by-products derived from the walnut tree contains flavonoids, phospholipids, sterols, triterpenes, quinones, oils, tannins, essential fatty acids (Fukuda et al., 2003; Amaral et al., 2004; Li et al., 2006; Stampar et al., 2006; Li et al., 2007; Pereira et al., 2007; Pereira et al., 2008; Cosmulescu and Trandafir, 2011; Fernández-Agulló et al., 2013; Tapia et al., 2013; Cosmulescu et al., 2014; Kafkas et al., 2017). Phenolic compounds such as pyrogallol, phydroxybenzoic acid, vanillic acid, ethyl gallate, protocatechuic acid, tannic acid, syringic acid, gallic acid, ferulic acid, trans-cinnamic acid, $o$-coumaric acid, $p$ coumaric acid, chlorogenic acid, and caffeic acid were also isolated from walnuts. Walnut has about 16 polyphenols, with antioxidant activity so protective that it is described as "remarkable". Free fatty acids, diglycerides, sterols, sterol esters, phosphatides and vitamins are present in minor quantities in walnut.

Due to composition of the fruit, the walnut is classified as a strategic nut crop for human nutrition and is included in the FAO list of priority plants (Gandev, 2007). The seed part of the fruit (kernel) is consumed fresh, toasted, or mixed with other confectionaries. Not only dry fruits (nuts) are used but also green walnuts, kernels, bark, green walnut husk and leaves have been used in both cosmetic and pharmaceutical industry (Stampar et al., 2006).

Our paper aimed to determine the variation in time of some composition parameters from the walnut leaves and the green walnut husk for different Juglans regia L. cultivars, harvested in 2018 from UCv-SCDP Vâlcea, Romania. For all analysed cultivars, the content of polyphenols, flavonoids and tannins from the walnut leaves and the green walnut husk was evaluated knowing that the identification and the quantification of the active compounds from these vegetal materials may explain their therapeutic effects, already observed clinically. Finally, the study reveals the mode of variation in the content of polyphenols, flavonoids and tannins during the developmental stages of the walnut leaves and the green walnut husk, emphasizing also the influence of $X a j$ bacterium.

\section{Materials and Methods}

\section{Plantmaterial}

Three Romanian cultivars 'Jupânești', 'Valrex' and 'Valmit' and French one 'Franquette' were analyzed. All four cultivars are vigorous, have terminal bearing and good productivity. The Romanian varieties have good resistance to low temperatures (up to $-30{ }^{\circ} \mathrm{C}$ ) while the French cultivar is less resistant to low temperatures. The Romanian varieties have the ripeness period of the fruit in September, the first decade of the month for 'Valrex' cv. and the second decade of the month for 'Jupâneşti' and 'Valmit' cvs. The 'Franquette' cv. presents a later maturity of the fruit as compared to the other cultivar, namely: the second decade of October. 'Franquette' and 'Jupâneşti' cultivars have elliptical nuts and the average weight of $12.1 \mathrm{~g}$ of dry in-shell nuts. 'Valrex' cv. has ovate shaped fruit and an average weight of $14.3 \mathrm{~g}$. 'Valmit' cv. has round fruit and a mean weight of $12.6 \mathrm{~g}$. More agronomical and genetic information about these cultivars were presented in our previous works (Giura et al., 2016a, b).
The walnut leaves and the green walnuts were sampled in early morning hours, and stored at $0-4^{\circ} \mathrm{C}$ until their use. Before being analysed, the walnut leaves and the green walnuts were washed and wiped with a paper towel. Then, the walnut leaves and the green walnut husk cut into pieces and transformed into a homogeneous mixture with a vertical mixer.

\section{Chemicalsubstances}

Gallic acid, catechin, tannic acid and Folin-Ciocalteu reagent were purchased from Redox Bucharest - Sigma Aldrich, Dako, Epp. Romania. Methanol, sodium hydroxide, sodium carbonate, sodium nitrite and aluminium chloride were purchased from Merck Romania SRL.

\section{Chemical analysis and equipment}

Quantitative determination of polyphenols was performed by spectrophotometric method using a UV-Vis spectrophotometer PerkinElmer Lambda25. The methodology proposed by Singleton and Rossi (1965) was respected. The method principle is based on forming a blue coloured compound between phosphotungstic acid and polyphenols, in an alkaline medium. For analysis, a methanolic extract of homogenised vegetal material with concentration $100 \mathrm{mg} / \mathrm{mL}$ was used. The concentration of polyphenols was calculated using the calibration curve, performed under the same conditions as the sample, using the absorbance values at the maximum absorption, located at $765 \mathrm{~nm}$. In order to obtain the calibration curve, a stock solution of gallic acid was used. $0.5 \mathrm{~mL}$ of the methanol extract of vegetal material was added to a $10 \mathrm{~mL}$ flask containing $7 \mathrm{~mL}$ of distilled water and $0.5 \mathrm{~mL}$ of FolinCiocalteu reagent. After 5 minutes of rest, $2 \mathrm{~mL}$ solution of sodium carbonate $10 \%$ was added. After 60 minutes of rest, absorbance of the samples was measured and the concentration of polyphenols was estimated. Finally, the content of polyphenols was expressed as mg gallic acid equivalent/ $100 \mathrm{~g}$ of vegetal material.

Quantitation of flavonoids was performed by spectrophotometric method using a UV-Vis spectrophotometer PerkinElmer Lambda25. The methodology proposed by Zhishen et al. (1999) was respected. The method principle is based on the formation of a yellow-orange-coloured compound by the reaction of flavonoids and aluminium chloride. For analysis, a methanolic extract of vegetal material with concentration $100 \mathrm{mg} / \mathrm{mL}$ was used. The concentration of the flavonoids has been calculated using the calibration curve, performed under the same conditions as the sample solutions, using the absorbance values of the maximum absorption, located at $510 \mathrm{~nm}$. To obtain the calibration curve, a stock solution of catechin was made. $1 \mathrm{~mL}$ of methanolic extract of vegetal material was added to a $10 \mathrm{~mL}$ volumetric flask containing 6 $\mathrm{mL}$ of distilled water and $0.5 \mathrm{~mL}$ of sodium nitrite $5 \%$. After 5 minutes of rest, in the volumetric flask was added $0.5 \mathrm{~mL}$ of aluminium chloride $10 \%$. After 5 minutes, $2 \mathrm{~mL}$ solution of sodium hydroxide $1 \mathrm{M}$ was added. The absorbance of the solution at $510 \mathrm{~nm}$ was measured. Flavonoids concentration was estimated using a calibration curve of catechin and, finally, the content of flavonoids was expressed as mg catechin equivalent $/ 100 \mathrm{~g}$ of vegetal material. 
1266

Quantitative determination of tannins was performed by spectrophotometric method using a UV-Vis spectrophotometer PerkinElmer Lambda25. The methodology proposed by Makkar et al. (1993) was used. For analysis, an aqueous extract of homogenised vegetal material with concentration $100 \mathrm{mg} / \mathrm{mL}$ was used. The concentration of tannins was calculated using the calibration curve, performed under the same conditions as the sample, using the absorbance values at the maximum absorption, located at $765 \mathrm{~nm}$. In order to obtain the calibration curve, a stock solution of tannic acid was used. 1 $\mathrm{mL}$ of the aqueous extract of vegetal material was added to a $10 \mathrm{~mL}$ flask containing $2 \mathrm{~mL}$ of distilled water and $2 \mathrm{~mL}$ of Folin-Ciocalteu reagent. After 5 minutes of rest, $5 \mathrm{~mL}$ solution of sodium carbonate $10 \%$ was added. After 60 minutes of rest, absorbance of the samples was measured and the concentration of tannins was estimated. Finally, the content of tannins was expressed as $\mathrm{mg}$ tannic acid equivalent/100 $\mathrm{g}$ of vegetal material.

\section{Results and Discussion}

Walnuts have antioxidant features due to the presence of some bioactive compounds, such as vitamin C, polyphenols, flavonoids, anthocyanins and carotenoids (Cernîşev and Şleagun, 2007). The level of these compounds in the body is an indicator of health; they operated as biomarkers food quality (Costin and Segal, 1999).

Composition of polyphenolic compounds within the by-products derivates from the walnut (Fukuda et al., 2003; $\mathrm{Li}$ et al., 2006) is quite well known. Polyphenolic compounds are a class of antioxidants that prevent oxidative damage to lipids and thus increase the nutritional value of the food (Tudor-Radu et al., 2016). They possess a broad spectrum of biochemical activities, such as antioxidant, antimutagenic and anticarcinogenic (Nakamura et al., 2003).

The evolution in time of the polyphenolic compounds content at the walnut leaves and the green walnut husk, both on healthy vegetal materials and attacked by $X a j$ is shown in Figs. 1 to 4. At the walnut leaves, in 15 June 2018, the content of polyphenolic compounds was found between $2510 \mathrm{mg}$ gallic acid equivalent/100 g of vegetal material 'Franquette' cv. and $7632 \mathrm{mg}$ gallic acid equivalent/100 g of vegetal material 'Jupâneşti' cv. The highest content of polyphenolic compounds in the walnut leaves was found at 27 July 2018 for all Romanian cultivars and at 17 August 2018 for French one. Pereira et al. (2007) and Cosmulescu et al. (2014) obtained similar results.

In the green walnut husk, the amount of polyphenolic compounds was lower compared to the values obtained from the walnut leaves. Thus, in 15 June 2018, the amounts of polyphenolic compounds between $1788 \mathrm{mg}$ gallic acid equivalent/100 g vegetal material 'Jupâneşti' and $2518 \mathrm{mg}$ gallic acid equivalent $/ 100 \mathrm{~g}$ vegetal material 'Valmit' were found. The highest content of polyphenolic compounds from the green walnut husks was found in 6 July 2018 for 'Valmit' and 'Valrex' cultivars and in 27 July 2018 for 'Jupănești' and 'Franquette' cvs. Oliveira et al. (2008) and Fernández-Agulló et al. (2013) obtained similar results.
At each sampling stage, the polyphenols content was found to be greater in the vegetal materials attacked by Xanthomonas arboricola pv.juglandis (Xaj) compared to the healthy vegetal materials.

Flavonoids are a large group of hydroxylated phenolic compounds distributed in green plant kingdom, being located in cell vacuoles. They are carrying out important functions in the plants. They are responsible for colour and aroma of flowers and fruits, which helps to attract pollinating insects. Flavonoids protect plants from different biotic and abiotic stresses. They are regulating cell growth and help for UV filtration, nitrogen fixation, cell cycle inhibition, as chemical messengers. Flavonoids have roles in frost hardiness and in drought resistance and may play a functional role in plant heat acclimation and freezing tolerance (Cushnie and Lamb, 2005; Samanta et al., 2011; Mierziak et al., 2014; Mathesius, 2018).

Figs. 5 and 6 indicates the modification in time of flavonoids content in walnut leaves, higher values of flavonoids content being recorded in walnut leaves attacked by Xaj. In 15 June 2018, the flavonoids content showed values between $187 \mathrm{mg}$ catechin equivalent/100 g of healthy vegetal material 'Jupâneşti' and $269 \mathrm{mg}$ catechin equivalent/100 $\mathrm{g}$ of healthy vegetal material from 'Valmit'. At this sampling stage, for the varieties attacked by Xaj, the flavonoids content showed values between $236 \mathrm{mg}$ catechin equivalent/100 g of vegetal material 'Jupâneşti' and $381 \mathrm{mg}$ catechin equivalent/100 g of vegetal material 'Valrex'. The highest content of flavonoids in the walnut leaves was found at 27 July 2018 for all Romanian cvs. and at 17 August 2018 for French one, both at the healthy vegetal material and attacked by Xaj.

In the green walnut shell, the flavonoids content was lower compared to the values obtained from the walnut leaves. Thus, in 15 June 2018, the flavonoids content was found between $38 \mathrm{mg}$ catechin equivalent/100 g of healthy vegetal material 'Valrex' and $67 \mathrm{mg}$ catechin equivalent/100 g of healthy vegetal material 'Franquette' while at the vegetal material attacked by $X a j$, the extreme values were $72 \mathrm{mg}$ catechin equivalent/100 g of vegetal material 'Valmit' and $123 \mathrm{mg}$ catechin equivalent/100 $\mathrm{g}$ of vegetal material 'Franquette'. The highest flavonoids content from the green walnut husk was found in 6 July 2018 for 'Valmit' and 'Valrex' cvs., in 27 July 2018 for 'Jupâneşti' cultivar and in 17 August 2018 for 'Franquette' cv.

Tannins are found in very small quantities in most plants and in large quantities they are found in the bark, the wood and the leaves of oak, alder, spruce, poplar, walnut. From a chemical point of view, tannins are polyphenolic compounds, water-soluble, astringent. They are secondary metabolites of vegetal materials, being either galloyl esters and their derivatives or oligomeric and polymeric proanthocyanidins (Khanbabaee and van Ree, 2001). In the vegetal organism, tannins play an important biochemical role because they increase the resistance of plants to viruses and microorganisms. Tannins have wide uses in medicine and leather industry. They have the antidiarrheal, antimycotic and antiseptic action as a result of the precipitation of bacterial and fungal proteins. They are antioxidants because they are highly reducing compounds (Chezem and Clay, 2016). 
At the walnut leaves, in 15 June 2018, the tannins content showed values ranging from $204 \mathrm{mg}$ tannic acid equivalent/100 g of vegetal material 'Jupâneşti' and $272 \mathrm{mg}$ tannic acid equivalent $/ 100 \mathrm{~g}$ of vegetal material 'Valrex'. The same tendency for variation of the tannins content was also observed in walnut leaves of the analyzed varieties attacked by Xaj. The highest tannins content in the walnut leaves was found at 27 July 2018 for all Romanian varieties and at 17 August 2018 for French one, both at the healthy and attacked leaves.

In the green walnut husk, the tannins content was lower compared to the values obtained from the walnut leaves. Thus, in 15 June 2018, the tannins content showed values ranging from $122 \mathrm{mg}$ tannic acid equivalent $/ 100 \mathrm{~g}$ of vegetal material 'Jupâneşti' and $222 \mathrm{mg}$ tannic acid equivalent/100 g of vegetal material 'Valrex'. In this moment, in the green walnut husk attacked by $X a j$, the tannins content showed values was ranging from $210 \mathrm{mg}$ tannic acid equivalent/100 $\mathrm{g}$ of vegetal material 'Valmit' and $326 \mathrm{mg}$ tannic acid equivalent/100 $\mathrm{g}$ of vegetal material 'Valrex', which attests to the fact that at 15 June 2018 the bacteria little attacked the 'Valmit' variety comparatively with the other varieties. The highest tannins content from the green walnut husk was found in 6 July 2018 for 'Valmit' and 'Valrex' varieties, in 27 July 2018 for 'Jupănești' cv. and in 17 August 2018 for the French cultivar, both at the healthy and attacked walnut husk. At each sampling stage, the tannins content was found to be greater in the green walnut husk attacked by Xaj compared to the healthy green husk.

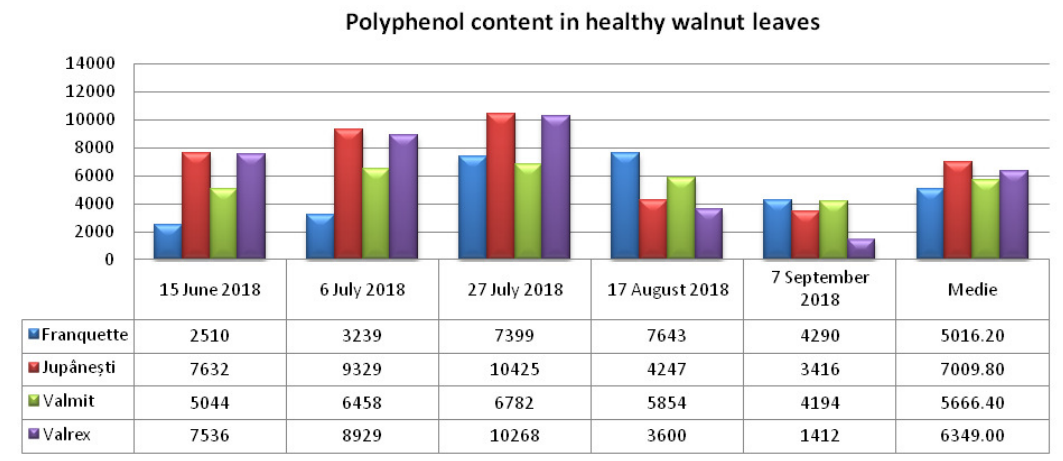

Fig. 1. Modification in time of polyphenol content (mg gallic acid equivalent/100 $\mathrm{g}$ of vegetal material) in healthy walnut leaves

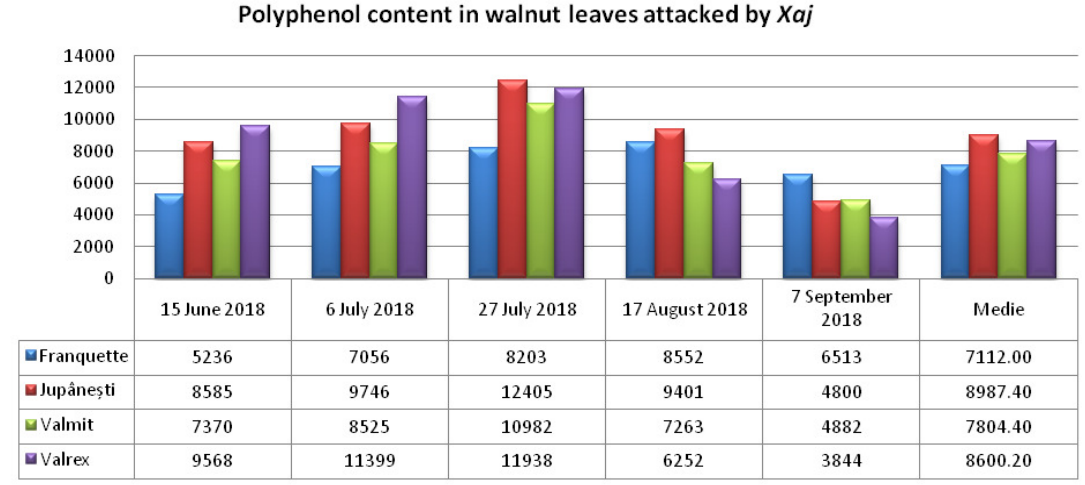

Fig. 2. Modification in time of polyphenol content ( $\mathrm{mg}$ gallic acid equivalent/100 $\mathrm{g}$ of vegetal material) in walnut leaves attacked by Xaj

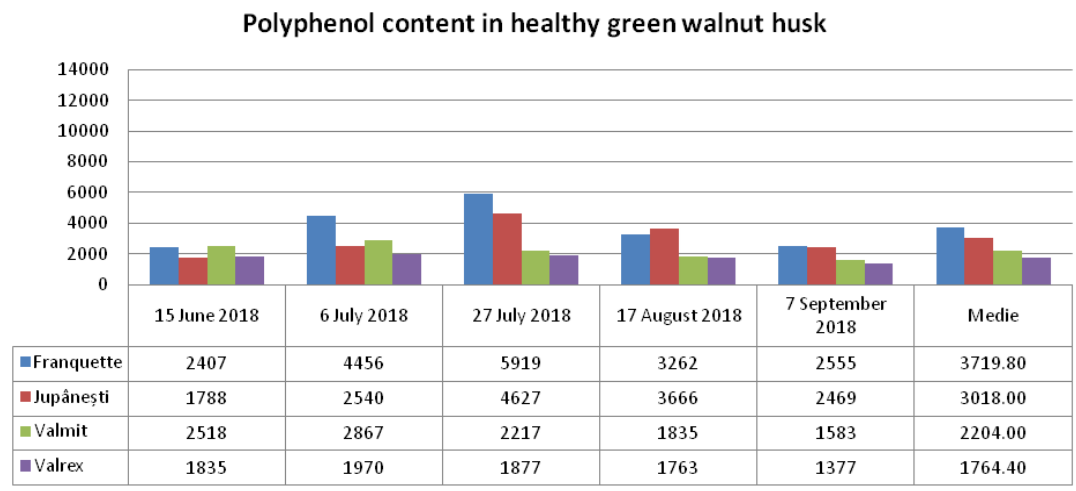

Fig. 3. Modification in time of polyphenol content ( $\mathrm{mg}$ gallic acid equivalent/100 $\mathrm{g}$ of vegetal material) in healthy green walnut husk 


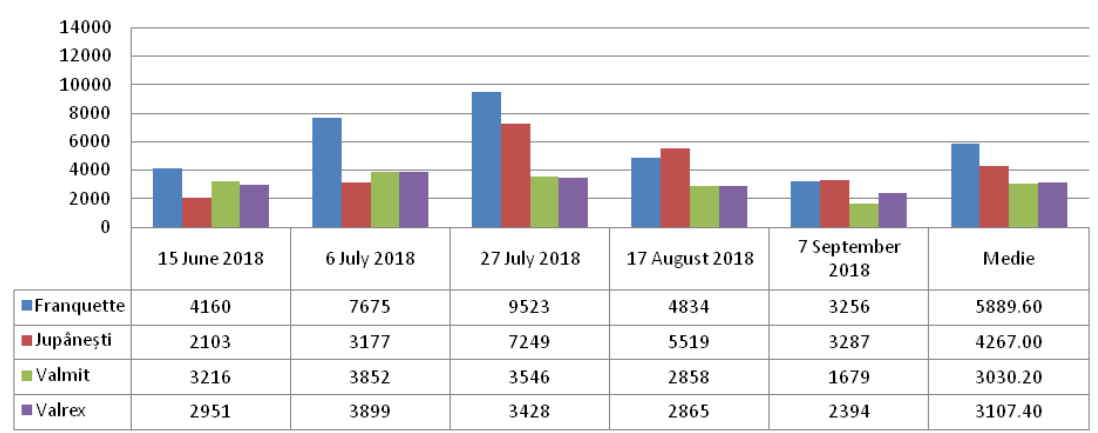

Fig. 4. Modification in time of polyphenol content ( $\mathrm{mg}$ gallic acid equivalent/100 $\mathrm{g}$ of vegetal material) in green walnut husks attacked by $X a j$

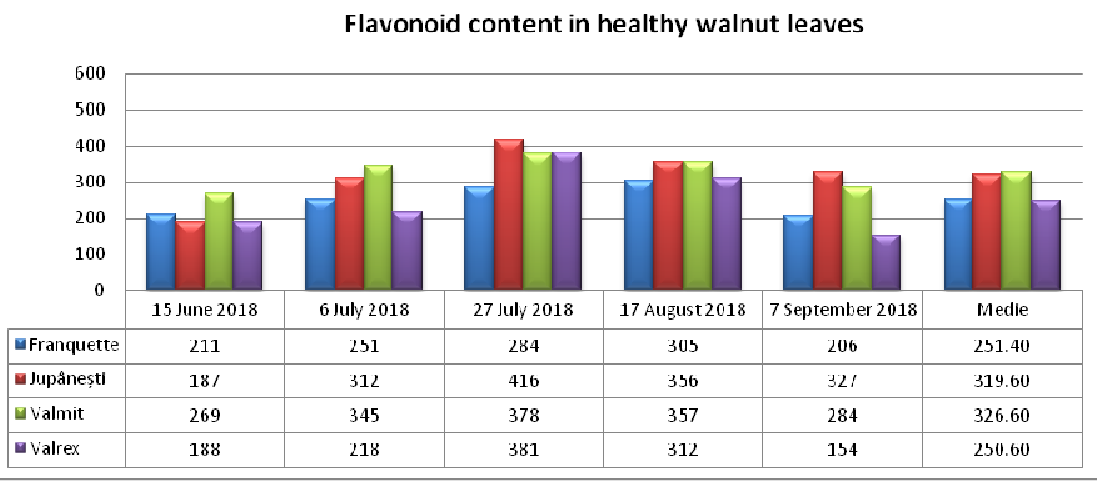

Fig. 5. Modification in time of flavonoid content (mg catechin equivalent/100 $\mathrm{g}$ of vegetal material) in healthy walnut leaves

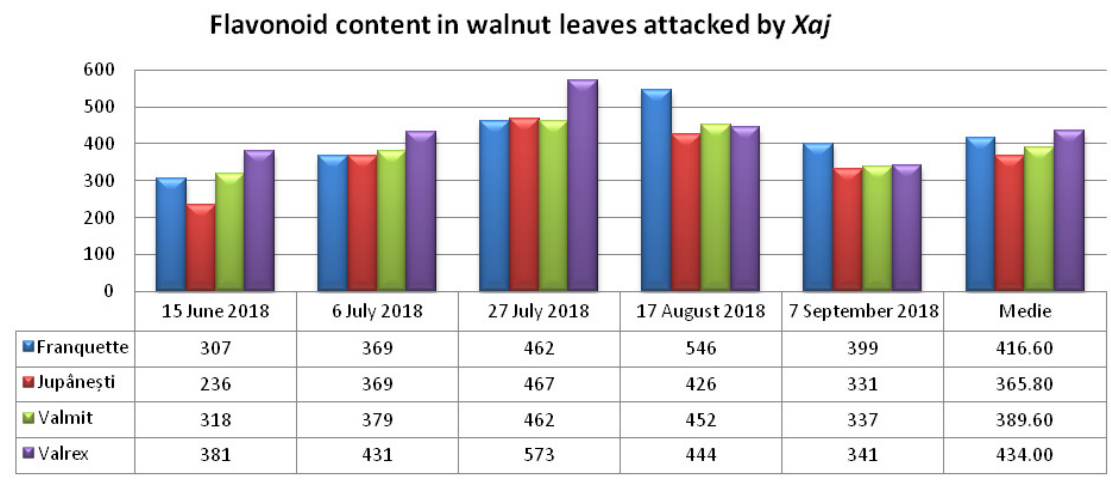

Fig. 6. Modification in time of flavonoid content ( $\mathrm{mg}$ catechin equivalent/100 $\mathrm{g}$ of vegetal material) in walnut leaves attacked by Xaj

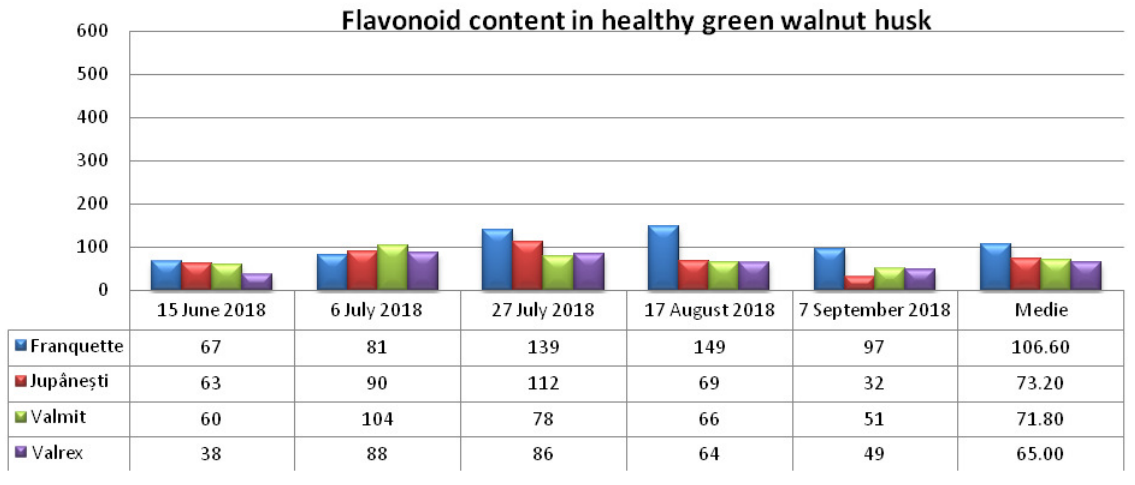

Fig. 7. Modification in time of flavonoid content ( $\mathrm{mg}$ catechin equivalent/100 $\mathrm{g}$ of vegetal material) in healthy green walnut husks 
Flavonoid content in green walnut husk attacked by $\mathrm{Xaj}$

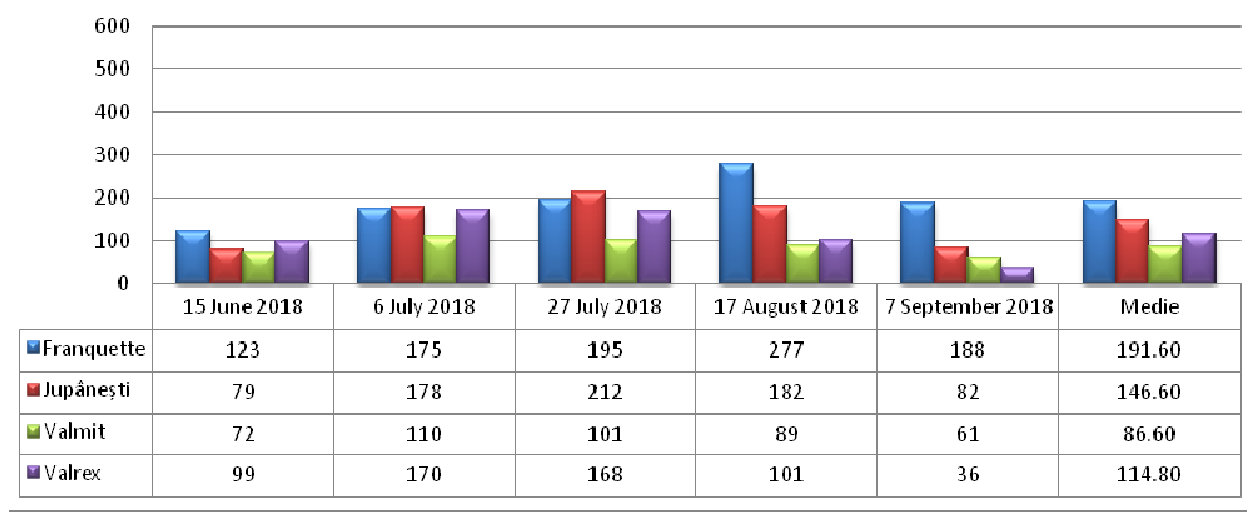

Fig. 8. Modification in time of flavonoid content ( $\mathrm{mg}$ catechin equivalent/100 $\mathrm{g}$ of vegetal material) in green walnut husks attacked by $X a j$

\section{Tannin content in healthy walnut leaves}

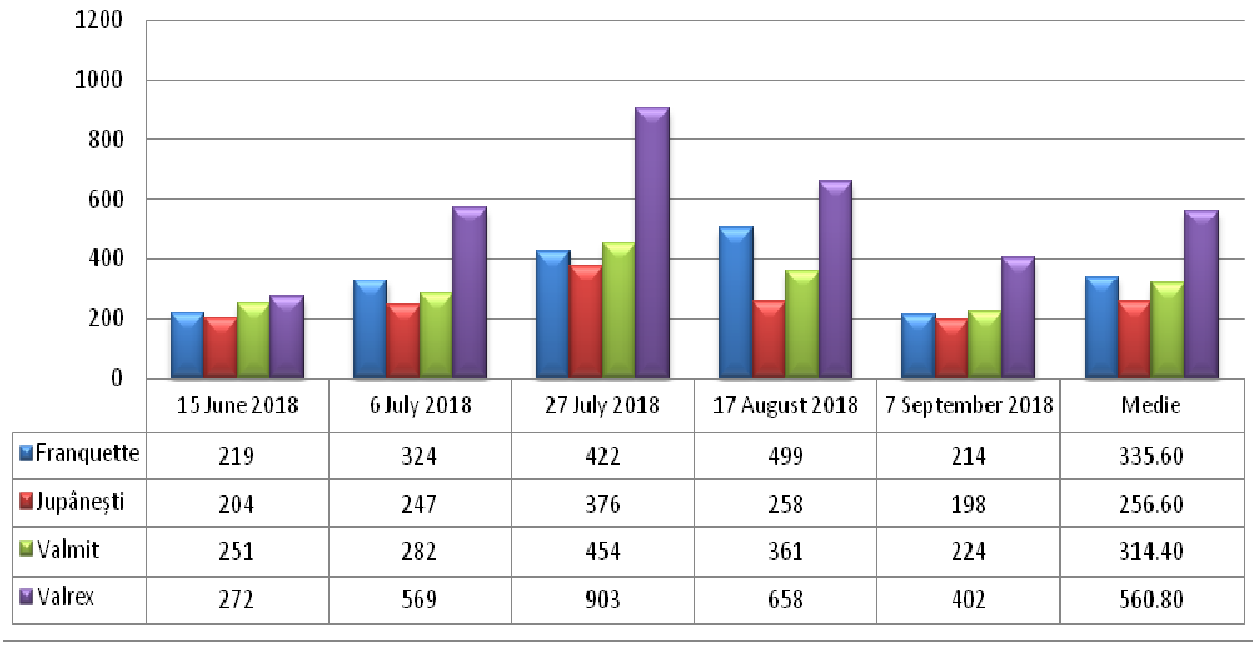

Fig. 9. Modification in time of tannin content ( $\mathrm{mg}$ tannic acid equivalent/100 g of vegetal material) in healthy walnut leaves

Tannin content in walnut leaves attacked by $X a j$

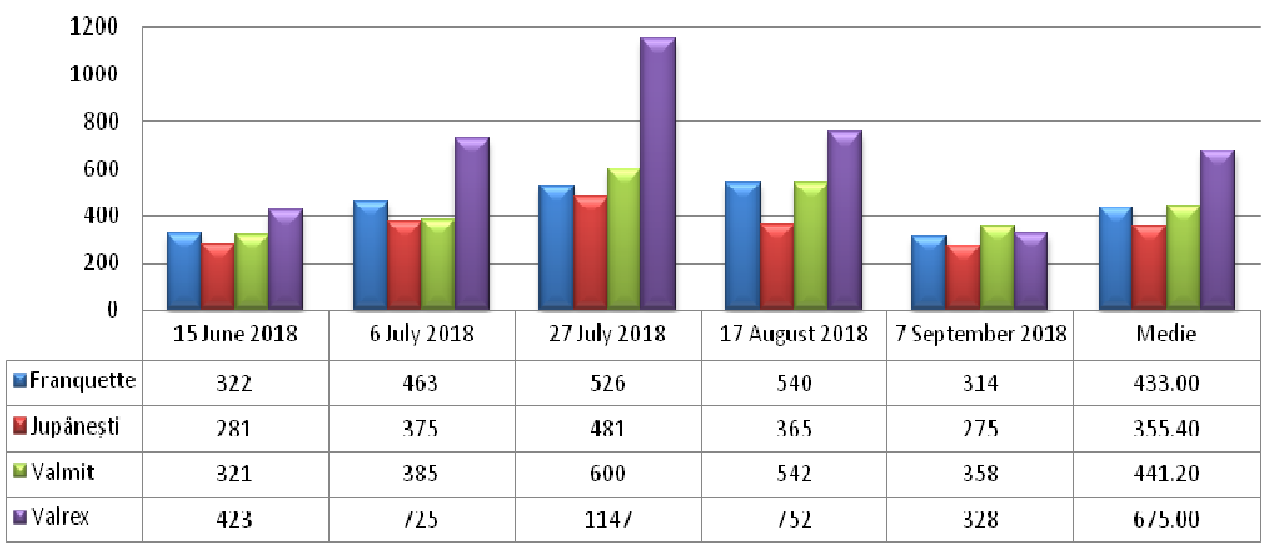

Fig. 10. Modification in time of tannin content ( $\mathrm{mg}$ tannic acid equivalent/100 $\mathrm{g}$ of vegetal material) in walnut leaves attacked by Xaj 
Tannin content in healthy green walnut husk

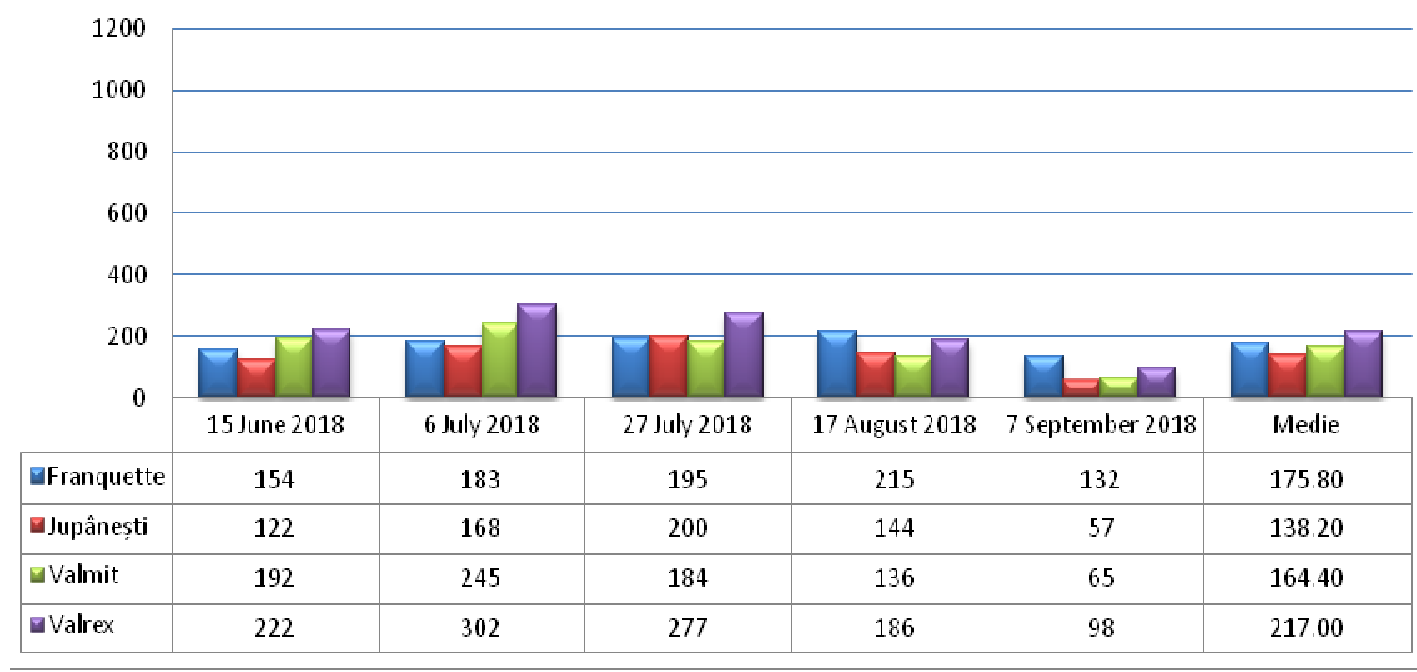

Fig. 11. Modification in time of tannin content ( $\mathrm{mg}$ tannic acid equivalent/100 $\mathrm{g}$ of vegetal material) in healthy green walnut husk

Tannin content in green walnut husk attacked by Xaj

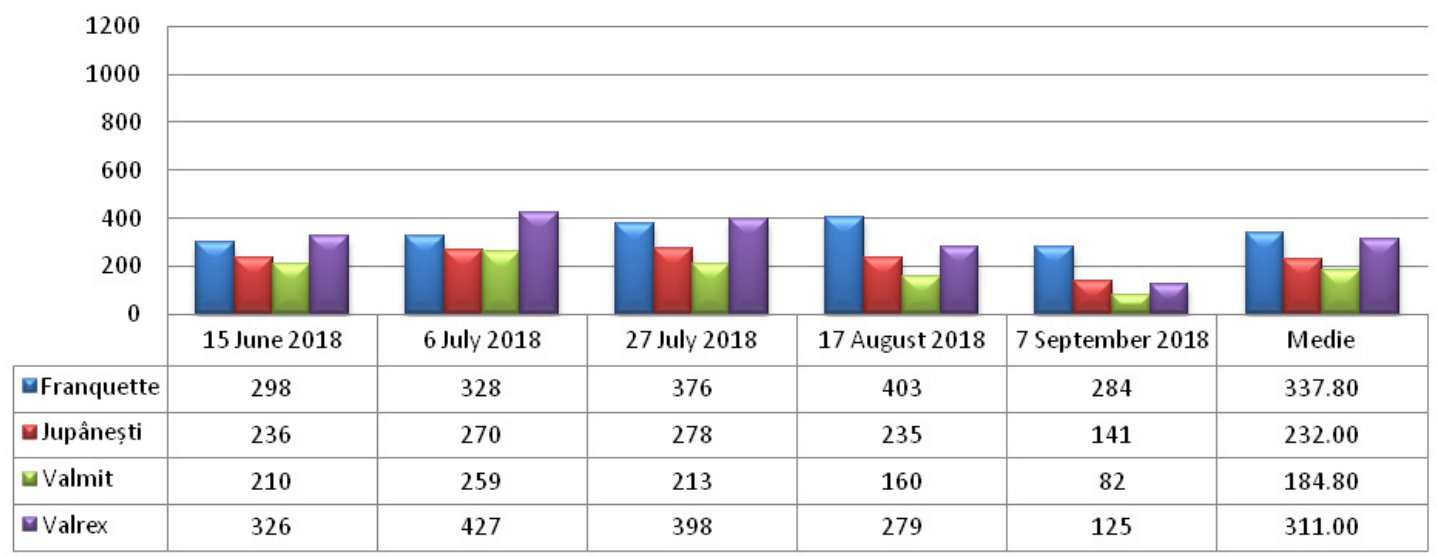

Fig. 12. Modification in time of tannin content (mg tannic acid equivalent/100 $\mathrm{g}$ of vegetal material) in green walnut husk attacked by $X a j$

\section{Conclusions}

The four walnut cultivars evaluated in this paper highlighted of variation in the content of polyphenols, flavonoids, and tannins, both in walnut leaves and in the green walnut husk, during the annual developmental stages of trees from June to September. An increase in the values of these composition parameters up to the maturity stage of each studied vegetal material was observed, followed by a decrease in the values for each analyzed parameter. At the same time, a higher content of biochemical compounds in the varieties attacked by Xaj compared to healthy vegetal materials was observed.
It can be emphasized that there is a correlation between the fruit maturity period of each walnut cultivar with the maturity period of both the walnut leaves and the green walnut husk, the 'Franquette' cv. having a later maturity compared to the Romanian cultivars.

In conclusion, the relatively similar behaviour of the four varieties of walnut taken in the analysis is determined by the cultivars characteristics because the walnuts were grown under the same climatic conditions and the same culture technology was applied.

\section{Conflict of Interest}

The authors declare that there are no conflicts of interest related to this article. 


\section{References}

Almeida IF, FernandesE, LimaJLFC, Costa PC, Bahia MF (2008). Walnut (Juglans regia) leaf extracts are strong scavenger of pro-oxidant reactive species. Food Chemistry 106(3):1014-1020.

Amaral JS, Seabra RM, Andrade PB, Valentão P, Pereira JA, Ferreres F (2004).Phenolic profile in the quality control of walnut (Juglansregia L.) leaves. Food Chemistry 88(3):373-379.

Cernîşev S, Şleagun G (2007). Influence of dehydration technologies on dried tomato biological quality and value. Cercetări Agronomice în Moldova XXXX 4(132):63-68.

Chezem WR, Clay NK (2016). Regulation of plant secondary metabolism and associated specialized cell development by MYBs and bHLHs. Phytochemistry 131:26-43.

Cosmulescu S, Trandafir I (2011). Variation of phenols content in walnut (Juglans regia L.). South Western Journal of Horticulture, Biology and Environment 2(1):25-33.

Cosmulescu S, Botu M, Achim G, Baciu A, Gruia M, Trandafir I (2014). Polyphenol content in walnut (Juglans regia $\mathrm{L}$.) mature leaves. Acta Horticulturae 1050:205-212.

Costin GM, Segal R (1999). Alimente funcționale. Editura Academica, Galați,pp39-71.

Cushnie TPT, Lamb AJ (2005). Antimicrobial activity of flavanoids. International Journal of Antimicrobial Agents 26(5):343-356.

Fernández-Agulló A, Pereira E, Freire MS, Valentão P, Andrade PB, Gonzáles-Álvarez J, Pereira JA (2013). Influence of solvent on the antioxidant and antimicrobial properties of walnut (Juglans regia L.) green husk extracts. Industrial Crops and Products 42:126-132.

Fukuda T, Ito H, Yoshida T (2003). Antioxidative polyphenols from walnuts (Juglansregia L.). Phytochemistry63(7):795-801.

Gandev S (2007). Budding and grafting of the walnut (Juglans regia L.) and their effectiveness in Bulgaria. Bulgarian Journal of Agricultural Science 13(6):683-689.

Giura S, Glodeanu MV, Mitrea R (2016). Reaction of walnut native genotypes to key attack of Xanthomonas campestris pv.juglandis (Pierce) Dye., under the climatic conditions Vâlcea area. Annals of the University ofCraiova - Agriculture, Montanology, CadastreSeries 46(2):131-136.

Giura S, Botu M, Mitrea R (2016). Reaction of some walnut genotypes grown in Vâlcea area at Gnomonia leptostyla Ces. et de not pathogen attack. Annals of the University ofCraiova - Agriculture, Montanology, CadastreSeries 46(2):137-143.

Kafkas E, BurgutA, Ozcan H, Ozcan A, Sutyemez M, Kafkas S, Türemis N (2017). Fatty acid, total phenol and tocopherol profiles of some walnut cultivars: a comparative study. Food and Nutrition Sciences 8(12):1074 1084 .

Khanbabaee K, van Ree T (2001). Tannins: classification and definition. Natural Product Reports 18(6):641-649.

Li L, Tsao R, Yang R, Liu CM, Zhu HH, YoungJC (2006). Polyphenolic profiles and antioxidant activities of heartnut (Juglans ailanthifolia var. cordiformis) and Persian walnut (Juglans regia L.). Journal of Agricultural andFood Chemistry 54(21):8033-8040.
Li L, Tsao R, Yang R, Kramer JKG, Hernandez M (2007). Fatty acid profiles, tocopherol contents, and antioxidant activities of heartnut (Juglans ailanthiofolia var. cordiformis) and Persian walnut (Juglans regia L.). Journal of Agricultural and Food Chemistry 55(4):1164-1169.

Makkar HPS, Blummel M, Borowy NK, Becker K (1993). Gravimetric determination of tannins and their correlations with chemical and protein precipitation methods. Journal of the Science of Food and Agriculture61(2):161-165.

Mathesius U (2018). Flavonoid functions in plants and their interactions with other organisms. Plants 7(2):30.

Mierziak J, Kamil Kostyn K, Kulma A (2014). Flavonoids as important molecules of plant interactions with the environment. Molecules 19(10):16240-16265.

Nakamura Y, Watanabe S, Miyake N, Kohno H, Osawa T (2003). Dihydrochalcones: evaluation as novel radical scavenging antioxidants. Journal of Agricultural and Food Chemistry 51(11):3309-3312.

Oliveira I, Sousa A, Ferreira ICFR, Bento A, Estevinho L, Pereira JA (2008). Total phenols, antioxidant potential and antimicrobial activity of walnut (Juglans regia L.) green husks. Food and Chemical Toxicology 46(7):2326-2331.

Pereira JA, Oliveira I, Sousa A, Valentão P, Andrade PB, Ferreira ICFR, ... Estevinho L (2007). Walnut (Juglans regia L.) leaves: phenolic compounds, antimicrobial activity and antioxidant potential of different cultivars. Food and Chemical Toxicology 45(11):2287-2295.

Pereira JA, Oliveira I, Sousa A, Ferreira ICFR, Bento A, Estevinho L (2008). Bioactive properties and chemical composition of six walnut (Juglans regia L.) cultivars. Food and Chemical Toxicology 46(6):2103-2111.

Samanta A, Das G, Das SK (2011). Roles of flavonoids in plants. International Journal of Pharmaceutical Science and Technology 6(1):12-35.

Singleton VL, Rossi JAJr (1965). Colorimetry of total phenolics with phosphomolybdicphospho-tungstic acid reagents. American Journal of Enology and Viticulture 16(3):144-158.

Stampar F, Solar A, Hudina M, Veberic R, Colaric M (2006). Traditional walnut liqueur - cocktail of phenolics. Food Chemistry95(4):627-631.

Tapia MI, Sánchez-Morgado JR, García-Parra J, Ramírez R, Hernández T, Gonzáles-Gómez D (2013). Comparative study of the nutritional and bioactive compounds content of four walnut (Juglans regia L.) cultivars. Journal of Food Composition and Analysis 31(2):232-237.

Tudor-Radu M, Vijan LE, Tudor-Radu CM, Tita I, Sima R, Mitrea R (2016). Assessment of ascorbic acid, polyphenols, flavonoids, anthocyanins and carotenoids content in tomato fruits. Notulae Botanicae Horti Agrobotanici Cluj-Napoca 44(2):477-483.

Zhishen J, Mengciheng T, Jianming W (1999). The determination of flavonoid contents in mulberry and their scavenging effects on superoxide radicals. Food Chemistry 64(4):555-559. 